\title{
Risk Factors Related to Road Traffic Accidents in Phuket Province, Southern Thailand: a Confirmatory Factor Analysis
}

\author{
JINDA KONGCHAROEN $^{\text {a }}$, NUTTHAJIT ONMEK ${ }^{\mathrm{b}}$, SEPPO KARRILA $^{\mathrm{a}}$ AND JARIYA SEKSAN $^{\mathrm{a}}$ \\ a. Faculty of Science and Industrial Technology, Prince of Songkla University, Surat Thani Campus, Surat Thani, \\ 84000, Thailand \\ b. Faculty of Science and Technology, Bansomdejchaopraya Rajabhat University, Bangkok, 10600, Thailand
}

\begin{abstract}
Phuket is an outstanding province in promoting its economy to domestic and international tourism in Thailand. An investigation of relevant factors for understanding the accident process is one approach to reduce traffic accidents and thereby support tourism industry. This study aimed 1) to examine the characteristics of traffic accidents, physical and surface conditions, and driving behavior in Phuket province; 2) to investigate for an in-depth understanding the factors related to road accidents, including human and vehicle factors, and environmental conditions; and 3) to construct and verify a model concordant with the empirical data. The research instruments were a structural questionnaire to drivers and a checklist assessment of the road surface conditions. A stratified random sampling technique was used for selecting the drivers. The data were statistically analyzed using exploratory factor analysis (EFA), confirmatory factor analysis (CFA), and second-order confirmatory factor analysis (SCFA). The majority of drivers were males (56.75\%), aged between 21 and 40 years $(57.00 \%)$, married $(62.25 \%)$, and working as company employees (73.25\%). The study revealed that nearly half $(47.15 \%)$ of the road traffic accidents in Phuket province involved
\end{abstract}

motorcycles, surpassing other types of vehicles. Traffic accidents were more likely to occur during the daytime (38.11\%), followed by night-time at $37.03 \%$. Guided by the EFA and CFA, the three categories of factors, namely human, environmental and vehicle factors, were confirmed as appropriate in fitted models. The results of SCFA revealed that almost all traffic accidents were caused by human factors, followed by environmental, and vehicle factors, in this rank order. The fitted model was concordant with the empirical data $(2 / \mathrm{df}=1.847, \mathrm{GFI}=0.972, \mathrm{AGFI}=0.951$, $\mathrm{CFI}=0.945, \mathrm{NFI}=0.890$, and RMSEA $=0.046$ ). Moreover, substandard road surfaces contributed to traffic accidents as an enabling factor. The responsible agency, therefore, should assist in improving the physical road conditions. Safety consciousness must be set as the default behavior for drivers to avoid accidents. Road accident reduction in Phuket province will increase the confidence among tourists for choosing Thailand as their tourist destination.

KEYWORDS: Human; Road Safety; Confirmatory factor analysis; Traffic accident; Exploratory factor analysis; Environment; Vehicle

\section{INTRODUCTION}

The World Health Organization (WHO, 2018) has presented that the most serious losses come from car and road accidents causing road deaths and injuries. A high rate of traffic accidents may cause losses in terms of psychological and social, economic, and humanitarian problems. The accident may be unexpected, unavoidable, and unintentional, but still more controllable than the other causes of premature death. Thailand is still ranked as one of the highest rates of road mortality in Asia. The rules of driving in the Western countries are strict, while those in Thailand are clement, and safe driving practices are not well adopted in Thailand. The impacts of accident involvement can vary by socioeconomic status, national culture, and region. The role of three types of factors, namely human component, vehicles and environment has been associated with road traffic accidents in many countries (Pakgohar et al., 2011; Verster \& Fourie, 2018; Zhang et al., 2013; Özkan et al., 2012; Sasfarzadeh \& Pooryari, 2006; Theofilatos \& Yannis, 2014; Liu et al., 2018;). The causes and factors contributing to traffic accidents in each region may be different for motorcyclists and drivers. The road and environmental factors, human and vehicle are all significant. Investigations of the relevant factors provide insights supporting safety improvements and their prioritization.

\footnotetext{
* Corresponding author. E-mail: jinda.suv@psu.ac.th
}

There are many theories related to accidents that are used in road traffic accident studies. For example, the Domino Theory is based on sequential factors and is the most famous theory for analyzing road accidents (Heinrich, 1959). Conceptually it involved three contributing components, including the social environment or background and ancestry, human error, and unsafe acts. The domino theory indicated that $88 \%$ of all accidents were caused by unsafe acts of people, $10 \%$ by unsafe conditions, and $2 \%$ were related with natural disasters, unpreventable causes, and others (Hosseinian \& Torghabeh, 2012; Saxena, N. 2017). In addition, the Haddon Matrix is a famous widely used model in the injury prevention field (Haddon, 1968). The three phases of accident occurrence were pre, during and post a road accident, involving all determinants of an accident that were attributable to human, equipment, and environment (Haddon, 1972). A previous study mentioned that people components were the evident underlying causal factors that led to an accident. Each of these components has relevance to the interactions with the root causes of accidents. Accidents can be prevented by identifying the main causes from the perspective of human, as influenced by equipment, and environment. The concepts of the Domino Theory and Haddon Matrix were adopted in this study and are used as reference points to investigate the intercorrelations among factors in accidents on Phuket island.

Several approaches are available to attitude and behavior theories, such as Theory of Planned Behavior (TPB), and Theory of Reasoned Action (Fishbein \& Ajzen 1975; Ajzen \& Fishbein 1980; Coogan, et al., 1992). Social psychology 
described people's attitudes towards behavior being based on their behavioral beliefs, normative beliefs, and control beliefs. Özkan, et al., (2012) studied the appropriateness of social psychological models for explaining behaviors in driving. A prior study had an application of the TPB to measure the attitudes of drivers toward four specific driving violations: speeding, tailgating, drunk driving, and dangerous overtaking (Parker, et al., 1992; Parker, et al., 1995). The attitudes and perceptions as important basic aspects indirectly or directly influenced behaviors in driving (Porter, 2011). The relationships between drivers' knowledge, attitude, and practice (KAP) regarding traffic regulations were evaluated against their deterministic effects on road traffic accidents (Mirzaei, et al., 2014; Lund, \& Aaro, 2004; Wicker, 1969). The attitude towards behavior was used as a framework reference to explain driver's behavior based on TPB. The psychological factors such as drivers' attitudes and unsafe driving behavior were considered in relation to road traffic accidents.

Numerous studies have focused on the factors influencing personal behavior for accident prevention, and have indicated that gender, age, driving experience and marital status etc. are significantly associated with safe driving (Uttra et al., 2020; Aden, 2019; Helal, et al., 2018; Zhang, et al., 2013). Risky behavior is a direct cause of road accidents, such as drunk driving, speeding, mobile phone use while driving, and motorbike rider not wearing a helmet, etc. There are many studies on risky driving behaviors, done both in Thailand and abroad (Mehdizadeh et al., 2018; Chumpawadee et al., 2015; Onmek et al., 2020; Yau, 2004; Wang et al., 2018; Stephensa, et al, 2017). Involvement of driving behaviors, knowledge, and attitudes regarding safety, on accidents was assessed, and evidence was found of significant relationships (Mohamed and Bromfield, 2017; Thasai et. al, 2021). As for equipment and facilities, they are considered common factors, separate from the human factor. Few studies on vehicle condition, inappropriate environment, and road characteristics, have been reported. This study was to examine the causes of the accidents from survey data, and to investigate the relationships among factors contributing to accidents along with risky behaviors.

Phuket island is the pearl of the Andaman Sea, in southern peninsular Thailand. It is a famous tourist center for foreign visitors, contributing significantly to income from tourism in Thailand: it is ranked as the second most popular tourist destination in Thailand (Vongurai, 2018). The tourism industry in the southern region drives growth in economy of Thailand by a variety of tourist attractions. Accidents that negatively impact the health of tourists are damaging to this image and function. The Royal Thai Police reported that 8,604, 9,606 and

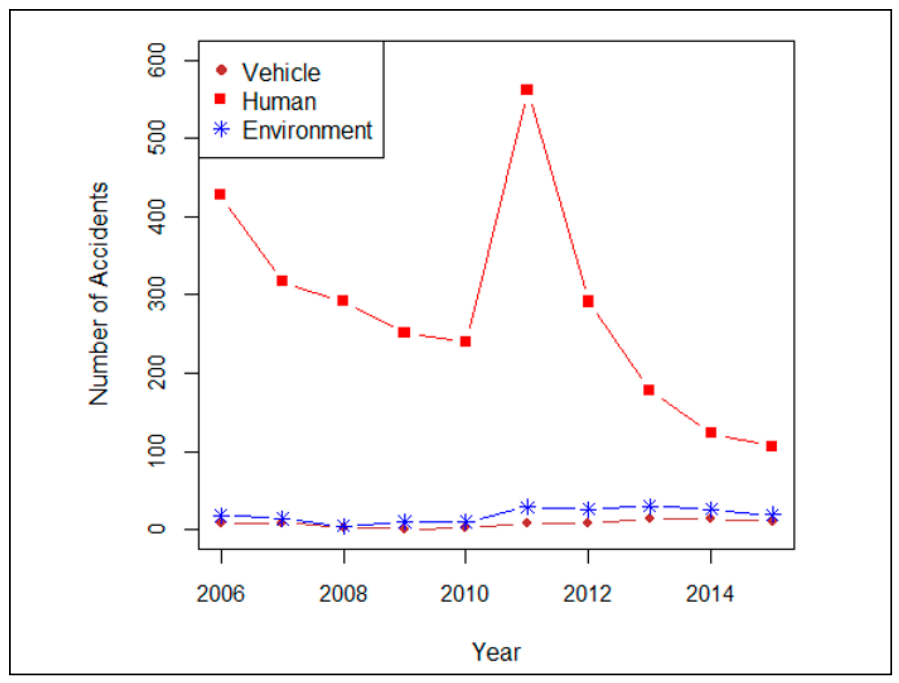

Figure 1 Causes of traffic accidents in Phuket (2006 - 2015)
10,206 road traffic accidents occurred on Phuket in the three years 2017, 2018 and 2019, respectively. The total costs to Department of Highways from property damage on Phuket were estimated at 3,841,000 Thai baht (about 0.1 million USD) in 2017. The accidents have direct and indirect costs, such as medical and hospital costs, insurance services, labor costs, and vehicle costs.

According to accident statistics from the Phuket Police Station reports in the past, the human factor was the dominant cause of road accidents, followed by environmental and vehicle factors. The numbers of accidents caused by the vehicle, and environment were quite low and stable while the number of accidents caused by human factor keep decreasing throughout the year except in 2011 (Figure 1). From the situation above, exploring associated vehicles and environmental factors was further pursued, as these potential risk factors are likely causing traffic accidents in Phuket.

Confirmatory factor analysis (CFA) is a multivariate statistics procedure that is widely used to investigate the construct validity of testing instruments, and it can be used to attempt to reduce the observed variables into a smaller number of latent factors (Schreiber et al., 2006; Atkinson et al.,2011). The CFA procedure includes defining an individual construct, designing a study to test the empirical results, and assessing the measurement model validity (Vanichbuncha, 2019). CFA is a useful tool for assessing validity of internal factor structure of measurement scales in the model. CFA had widespread applications in education research (Thanakarnpanich, 2013; Kongcharoen et al., 2020), and it can be used to provide evidence of intercorrelated data in medical research (Bentler \& Stein, 1992; Siriattakul, 2014) and in transportation (Gunson et al., 2019; Mohamed \& Bromfield, 2017; Suraji \& Tjahjono, 2012). For analyzing the model, second-order CFA (SCFA) can indicate a causal flow from the main construct to the first-order factors. This also helps estimate the structural relationships between the construct and the underlying sub-constructs (Hair et al., 2014). SCFA tested a theory-based statement for the structures of association among the first-order CFA as component of a hierarchical solution (Brown, 2015). The difference between CFA and SCFA was that CFA was defined by the observed variables, while SCFA can be used to focus on more dimensions and different perspectives. Therefore, SCFA is performed in this study to validate the model by examining the relationships among the variables.

The contribution of this study is an examination involving physical and surface conditions of roads that have often been ignore among the causes of traffic accidents, while changing or improving them is easier than adjusting human behaviors. This study also investigated candidate contributing factors as determinants of road traffic accidents, including psychological factors such as attitudes toward environment and

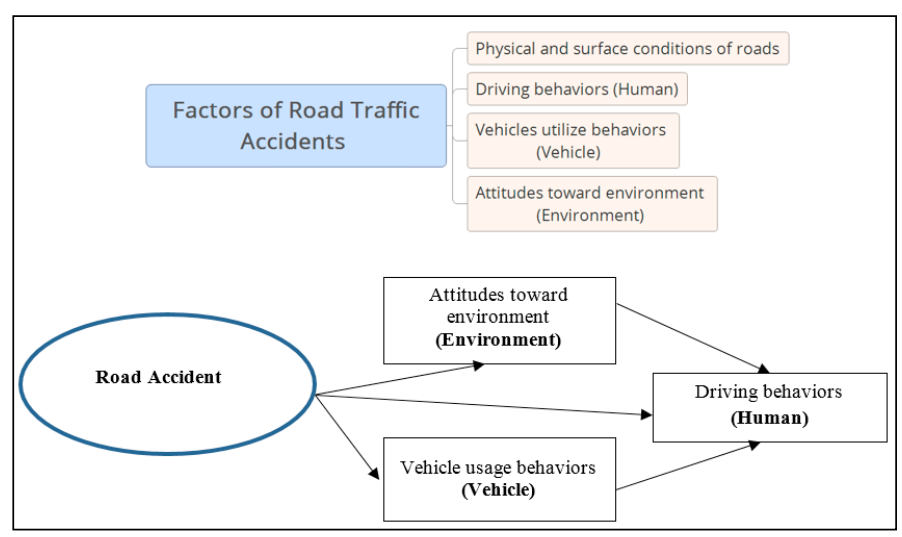

Figure 2 The conceptual framework and hypothetical model of the study 
driver behaviors, to provide an in-depth understanding of factors related to accidents of people in Phuket province, by using SCFA. The information can support accident prevention strategies to reduce both incidence rate and severity of traffic accidents. The brand image of a safe road environment in Phuket province is of vital importance to its tourism business.

The following hypotheses were set up to represent the relationships among drivers' attitudes toward environment, behaviors regarding vehicle safety, and driving behaviors, in context of accidents as shown in Figure 2.

\section{DATA SOURCES AND METHODS}

In order to study prior traffic accidents, data were requested from the Royal Thai Police, the Reginal Center of the Highway Department, the Phuket Police Station and Department of Land Transport. Since the reports from the Phuket Police Station and the Royal Thai Police lacked the behavior of drivers and the evaluation of road and environment, a survey was further conducted to support exploring their effects on the traffic accidents. Primary data were collected by questionnaire surveys for measuring driving behaviors, and by assessing physical and surface conditions of roads.

The target population of this survey consisted of all those who had a driving license in Phuket, covering the three districts Mueang Phuket $(\mathrm{N}=238,866)$, Kathu $(\mathrm{N}=55,767)$, and Thalang $(\mathrm{N}=99,536)$. The sample consisted of 400 drivers, with this sample size based on Taro Yamane's formula (Yamane, 1973), and stratified random sampling was used. The number of samples by district are 242, 57, and 101 people, for Mueang, Kathu, and Thalang, respectively. The participation was under voluntary basis. This research employed the two instruments including checklist and questionnaire survey for measuring unsafe driving behavior based on Thai Health Promotion Foundation, ThaiRoads Foundation, the Driver Behavior Questionnaire: DBQ. (Reason et al., 1990; Habibi et al., 2014; Wallston \& Wallston, 1978; Suangka, 2016; Sullman \& Stephens, 2013; Rosli, et al., 2017).

I) The checklist of visual inspection ratings for surface conditions consisted of 4 aspects (4S) namely service, scenic, sure, and safe. The evaluation criteria were based on the level of Department of Rural Roads in Thailand. Visual condition rating was classified into the four categories A: Excellent; B: Good; C: Fair and D: Improvement.

II) The questionnaire survey consisted of four sections. The first part asked questions related to demographic information, such as gender, age, marital status, occupation, and monthly income. The second part included information on accidents, including holding of a driving license, types of vehicles, times of accidents, and accident experience. The third part gathered information on risky driving behaviors and vehicle usage behaviors (Table 1). Risky driving behaviors were measured using 24 items with five-point Likert scales, such as speeding, aggressive driving under a relevant emotional state, violation of the road laws, risk taking as concern for others. The last part included attitudes toward environment in 9 questions, with each question having a score from 1 to 5 points. Reliability of test results was assessed with Cronbach's alpha and the overall reliability coefficient was 0.789 , indicating high reliability of our sample data and good internal consistency.

\section{Data Analysis}

Demographic characteristics, driving behaviors and visual condition ratings were analyzed by using descriptive statistics. The measurement model was based on exploratory factor analysis, and confirmatory factor analysis (CFA) was used to test the validity of the model fit to the empirical data. Second-order CFA was applied to examine the hypothesized framework in this study.

\section{RESULTS}

3.1 The assessment of physical and surface conditions of roads in high-risk accident areas

On investigating the causes of traffic accidents in Phuket, an examination of physical and surface conditions of roads was necessary. According to the report of Phuket Provincial Police, the four most accident-prone areas were Bangkok Hospital Phuket (Area I), Phuket Rajabhat University (Area II), Rang Hill viewpoint (Area III) and Patong Hill (Area IV) as Figure 3. To study the current situation regarding physical and surface conditions in Phuket. In this study, visual inspection ratings were used to assess the roads within a 5-kilometer radius in each area. The results are displayed in Table 2.

This study revealed that Area I was good at level B because there were only low miscellaneous distresses found. In Area II, pavement marking, road delineator, and guidepost needed improvements, for level C. The Area III was similar to Area IV. These areas were good at level $\mathrm{C}$ in most aspects. In summary, these findings suggested that the surface defects, land to shoulder drop-off, repair of road lighting, and horizontal curves were significant factors begging for road maintenance. Moreover, the road infrastructure should be considered, especially in Areas II, III and IV, with immediate effect, to address surface defects, land to shoulder drop off, road lighting, and safety guard devices.

\begin{tabular}{lcl}
\hline Factors & Total Items & Example \\
\hline Human: & 18 & - using mobile device while driving \\
risky driving behaviors & & - get angry and drive too close to the vehicle in front \\
& \\
& $\begin{array}{l}\text { - disregard the speed limits in the early hours of morning or late } \\
\text { in the evening } \\
\text { etc. }\end{array}$
\end{tabular}

Vehicle:

behaviors of vehicle utilization
6

- the vehicles has poor brakes

the vehicles had flat tire or degraded tires

improving the visibility of vehicles etc.

Scoring
5-point Likert scales,
5: always, 4: often,
3: sometimes,
2: rarely, 1: never

5-point Likert scales,
5: always, 4: often,
3: sometimes,
2: rarely, 1: never

5-point Likert scales,

5: strongly agree,

4: agree, 3: undecided,

2: disagree,

1: strongly disagree 


\begin{tabular}{lcccc}
\hline & I & II & III & IV \\
\hline $\begin{array}{l}\text { 1. Surface defects and miscellaneous } \\
\text { distresses }\end{array}$ & B & C & C & C \\
\hline
\end{tabular}

\begin{tabular}{llllll}
\hline 2. Improvement of roadway geometry e.g. & B & C & B & C
\end{tabular}
patching

\begin{tabular}{lllll}
\hline 3. Land to shoulder drop off & B & C & C & C \\
\hline 4. Traffic signals and road signs & A & A & A & A \\
\hline 5. Mowing and cutting the trees for scenic & B & C & C & B \\
\hline 6. Pavement marking, road delineator, & B & D & B & B
\end{tabular}
guidepost reflectors

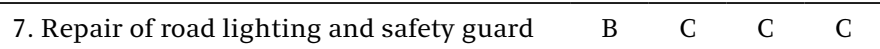
devices

Note: $\mathrm{A}=$ excellent; $\mathrm{B}=$ good; $\mathrm{C}$ = fair; $\mathrm{D}=$ poor

Table 2. The visual inspection ratings on Phuket, for most accidentprone areas

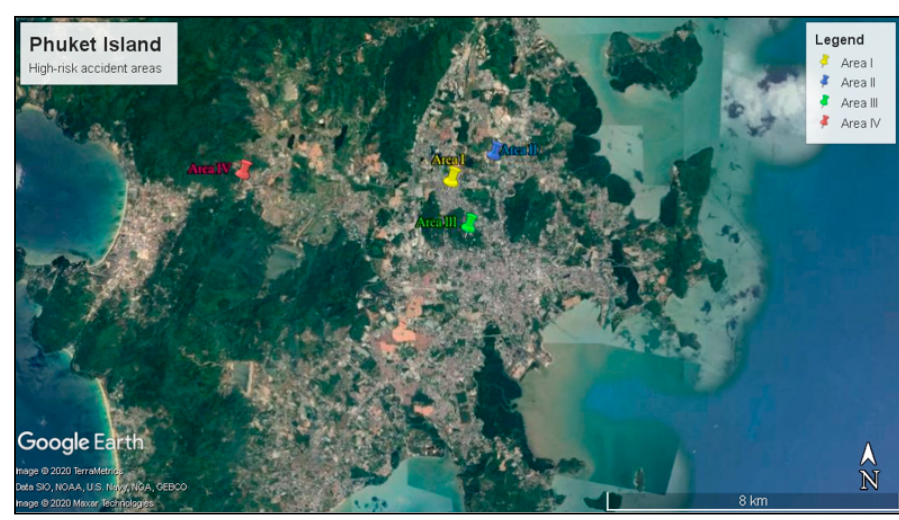

Figure 3. The high-risk accident areas marked on Phuket island (using Google Earth Pro)

\subsection{Demographic information and personal characteris tics in accidents}

Demographic characteristics are displayed in Figure 4. The study involved 400 people, with males representing $56.75 \%$ and ages $21-30$ years representing $30.75 \%$, followed by $31-40$ years for $26.25 \%$. In terms of marital status, $62.25 \%$ were married. $73.25 \%$ of the occupations were company employ-

\begin{tabular}{|c|c|c|c|}
\hline \multicolumn{2}{|c|}{ Characteristic } & \multirow{2}{*}{$\frac{\text { Frequency }}{41}$} & \multirow{2}{*}{$\begin{array}{c}\text { Percentage } \\
10.25\end{array}$} \\
\hline years of driving & $<4$ years & & \\
\hline & 4 - 6 years & 63 & 15.75 \\
\hline & 7 - 9 years & 49 & 12.25 \\
\hline & $>9$ years & 247 & 61.75 \\
\hline \multirow[t]{3}{*}{ licensed driver } & motorcycle driving & 226 & 56.50 \\
\hline & automobile driving & 137 & 34.25 \\
\hline & no & 37 & 9.25 \\
\hline \multirow[t]{3}{*}{ type of vehicle } & 2 wheels & 239 & 47.14 \\
\hline & 4 wheels & 161 & 31.76 \\
\hline & $>4$ wheels & 107 & 21.1 \\
\hline \multirow[t]{3}{*}{ severity } & property damages & 159 & 32.32 \\
\hline & slight injuries & 232 & 47.15 \\
\hline & serious injuries & 101 & 20.53 \\
\hline \multirow{3}{*}{$\begin{array}{l}\text { time of the } \\
\text { accidents }\end{array}$} & 06:00 am - $11.59 \mathrm{am}$ & 92 & 24.86 \\
\hline & $12: 00 \mathrm{pm}-05.59 \mathrm{pm}$ & 141 & 38.11 \\
\hline & $\begin{array}{l}\text { 06:00 pm - } 05.59 \\
\text { am }\end{array}$ & 137 & 37.03 \\
\hline \multirow{3}{*}{$\begin{array}{l}\text { duration of } \\
\text { recovery } \\
\text { from accidents }\end{array}$} & $<1$ week & 232 & 65.54 \\
\hline & $2-3$ weeks & 86 & 24.29 \\
\hline & > 3 weeks & 36 & 10.17 \\
\hline
\end{tabular}

Table 3. Summary statistics of drivers

ees, government officers and state enterprise employees. The majority (55.25\%) had monthly income 10,000 - 30,000 baht per month.

Most drivers had over 9 years of driving experience and used private motorcycles for travel. $56.50 \%$ had a motorcycle driving license and $34.25 \%$ had an automobile driving license (Table 3 ). The participating drivers in this study were local people and driving vehicles for a moderately long time. Drivers usually paid fines to the police for not wearing a helmet (28.00\%) or for not carrying a driving license (11.8\%). Among these drivers, $47.15 \%$ reported having a motorcycle accident during the last year with slight injuries. There was a dramatic increase in the number of slight injuries from traffic accidents in Phuket, from under 3,207 annual cases to around 5,622

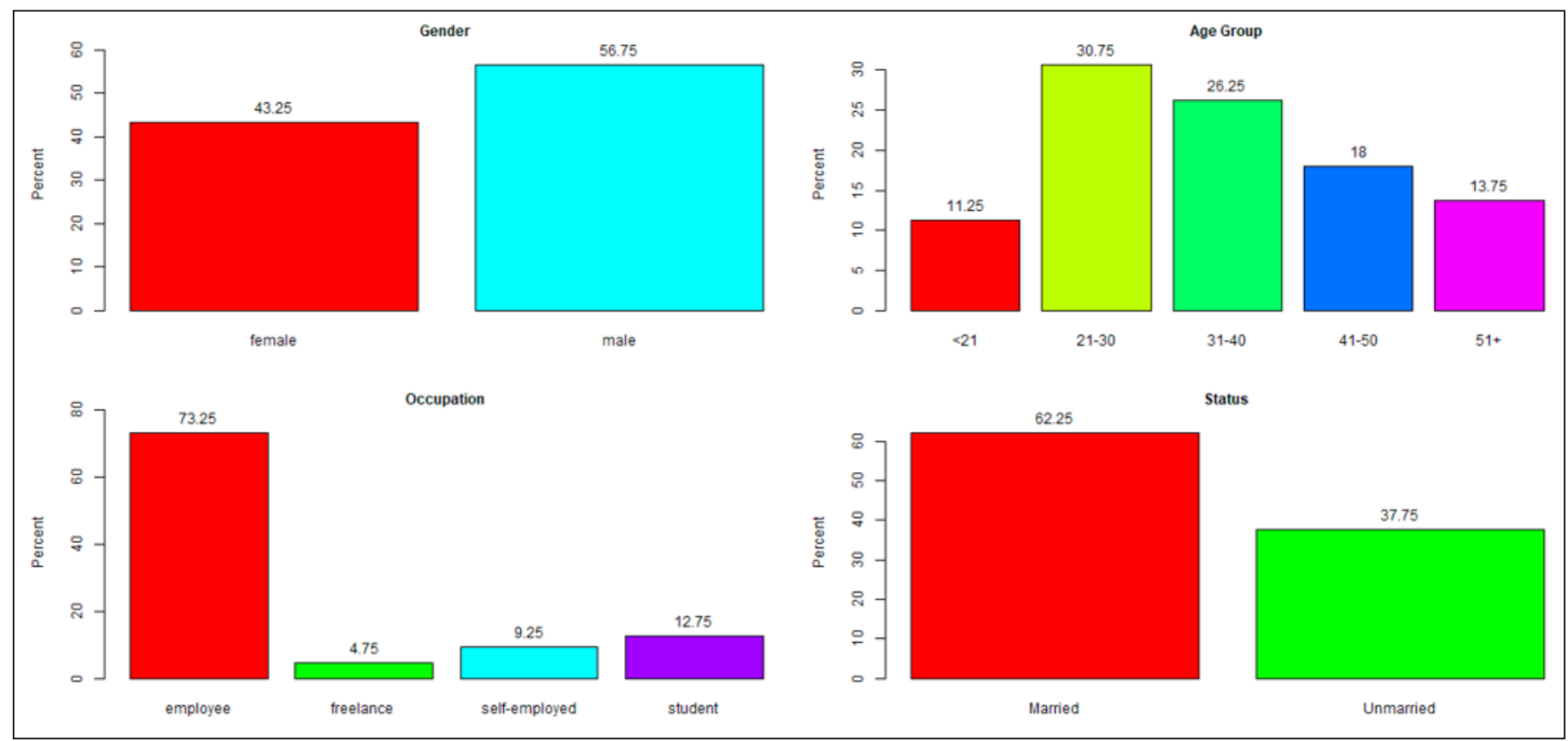

Figure 4. Demographic characteristics 
cases during 2012 to 2017, an increase of about 2,000 cases in 5 years (Royal Thai Police, 2018). In Thailand, motorcyclists are vulnerable accounting for $80 \%$ of the traffic fatalities from Thailand Accident Research Center (TARC). The contributing causes of motorcycle accidents were more likely to cause slight injuries than with other vehicles. Department of Land Transport of Phuket reported that the greatest number of registered vehicles in 2017 was 287,884 motorcycles. The findings were supported by previous reports on accidents by TARC, in that motorcycle accidents were the most common accident type. These results indicated that the time of an accident was mostly in the daytime $(12: 00 \mathrm{pm}-05: 59 \mathrm{pm})$ at $38.11 \%$, followed by night-time $(06: 00 \mathrm{pm}-05: 59 \mathrm{am})$ at $37.03 \%$. Perhaps, the drivers were hurrying back home from the workplace. Heavy traffic caused road traffic accidents. This study revealed that when traffic accidents were linked to motorcycles, slight internal injuries were involved. The detention in the hospital or home was less than 1-week, covered by lifetime medical care, and the healthcare expenses were low.

\subsection{Confirmatory factor analysis}

To further investigate whether there was any association among behavior of driving, vehicle usage behavior and at titudes of environment, confirmatory factor analysis was applied. Firstly, the data were analyzed by explanatory factor analysis (EFA) to filter observed variables of the same group and guide unobserved (latent) variables to fit with the model. The results revealed three-factor structures for measuring accidents were appropriate, with KMO (Kaiser-Meyer-Olkin statistic) at 0.869 and Bartlett's test of Sphericity had a significance level of 0.05 . The average variances extracted (AVE) were all above 0.5 , composite reliabilities (CR) were all above 0.7 , and the CR were greater than the AVE. The results are summarized in Table 4.

After the EFA process, a confirmatory factor analysis (CFA) was employed to verify the measurement model. CFA was also conducted to investigate the reliability and validity of the observed variables in relation to the unobserved constructs for the research variables. Using a maximum likelihood procedure, the results of CFA models were examined with model $t$ statistics including Chi-square value, goodness of fit index (GFI), comparative fit index (CFI), adjusted goodness of fit index (AGFI), normal fit index (NFI), and root mean square error of approximation (RMSEA) (Vanichbuncha, 2019; Brown, 2015). All fit indices were acceptable by the threshold levels; $\chi^{2} / \mathrm{df}=1.903, \mathrm{GFI}=0.973$, AGFI $=0.950$, $\mathrm{CFI}=0.943$, NFI $=0.890$, RMSEA $=0.048$. As a result, the first-order measurement model established an acceptable model fit. The hypothesis was tested using the criteria of goodness-of- t statistics.

There was a relationship among the driving behaviors of human, environmental, and vehicle conditions. The results of CFA pointed out that the driving behavior factor related to environmental factor was the most significant (regression weight $=0.98$ ); followed by the driving behavior factor related to vehicle factor (regression weight $=0.79$ ), as presented in Figure 5(a). In addition, there was a relation between the environmental and vehicle factors with regression weight of 0.70 . The driving behavior factor was positively correlated with the vehicles and environmental factors, and the association between vehicles and environmental factors was statistically significant. Causes of accidents related to drivers on Phuket island were aggressive driving: A2 (regression weight $=0.66$ ), speedy driving: A1 (regression weight $=0.60$ ), using unsafe vehicles: B1 (regression weight $=0.59$ ) and poor road conditions: C3 (regression weight $=0.47$ ). Drivers had a habit of driving dangerously, speeding, and overtaking with risk and with poor equipment, excessive load, and driving against the flow of traffic.

Overall, the fitness indices for the model demonstrated that the second - order model fit was good, with a reasonable level of overall fit to the empirical data. The validation of fitted model yielded a chi-square value of 1.847 for the second-order model, which was below the threshold of 3.0. The values of GFI, AGFI, CFI, NFI and RMSEA were 0.972, 0.951, 0.945,

\begin{tabular}{lccl}
\hline Latent variable & Symbol & Observed variable & AVE \\
\hline $\begin{array}{l}\text { Driving behavior } \\
\text { (Human) }\end{array}$ & & & CR \\
0.51 & 0.81
\end{tabular}

(Human) A1 speedy driving e.g. running red light, exceed the speed limits, disregard the speed limits late in the early hours of the morning or evening

A2 aggressive driving under a relevant emotional state e.g. get angry and drive too close to the vehicle in front, give chase to the vehicle next to, ride against the flow of traffic, make sudden lane changes by cutting in front of another vehicle

A3 negligent driving e.g. after alcohol consumption, being drowsy, driver fatigue, using mobile device while driving, braking too strongly on a slippery road

A4 violation of traffic rules e.g. drive too fast in overtaking-prohibited area, disregard of traffic sign, lack of driving license, violation of the traffic signals

Vehicle usage behavior (Vehicle) using unsafe vehicles e.g. poor equipment, vehicle misuse, exceeding load, lack of seatbelt or child seats

B2 modifications of vehicle e.g. loss of reflective cat's eyes, front-rear lights

B3 lack of maintenance e.g. fuel leakage, door not opening without rescue tools, dilapidated devices

Attitudes of

environment (Road) lack of street materials e.g. traffic lights, road signs, traffic control devices, lighting conditions, guard rail installation

C2 unfavorable weather e.g. rainfall, excessive heat, wind speed

C3 poor road conditions e.g. uneven road surfaces, broken concrete, road cracks, exposed rebar

Note: Average Variance Extracted (AVE), Composite Reliability (CR)

Table 4. Construct validity test 


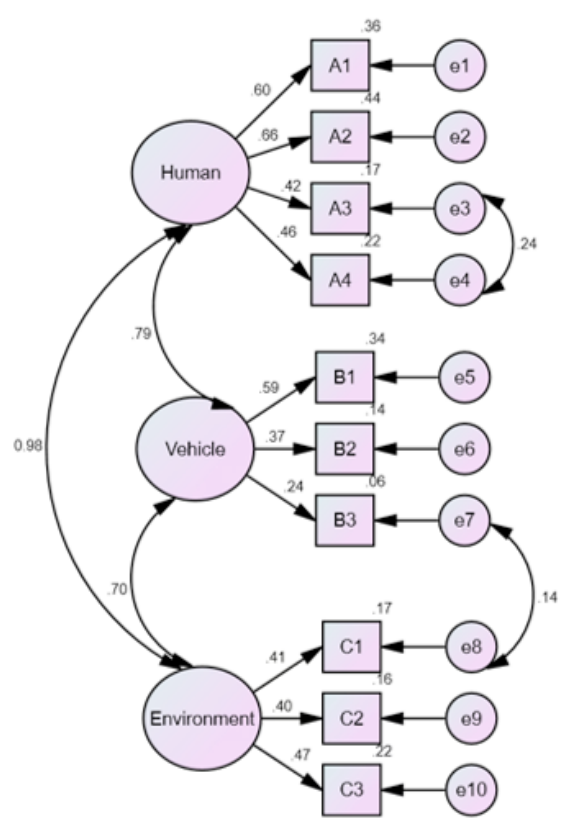

(a)

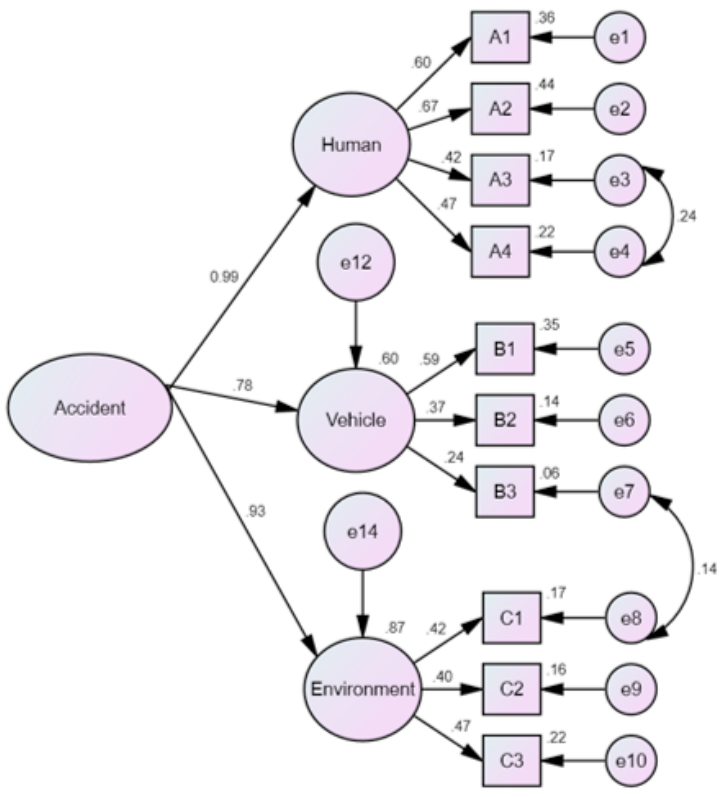

(b)

Figure 5. First-order (a), and second-order (b) CFA (Standardized Coefficient)

\begin{tabular}{|c|c|c|c|c|c|}
\hline Factor/Cause & Estimated Loading & S.E. & C.R. & $p$ & Standardized Estimate \\
\hline Driving behavior & 1.000 & & & & 0.990 \\
\hline Vehicle & 0.650 & 0.092 & 7.702 & $* * *$ & 0.777 \\
\hline Road \& environment & 0.609 & 0.091 & 6.717 & $* * *$ & 0.932 \\
\hline A1: Speedy driving & 0.876 & 0.101 & 8.802 & $* * *$ & 0.603 \\
\hline A2: Aggressive driving & 1.000 & & & & 0.665 \\
\hline A3: Negligent driving & 0.637 & 0.098 & 6.476 & $\star \star \star *$ & 0.417 \\
\hline A4: Violation of traffic rules & 0.725 & 0.099 & 7.146 & $* \star *$ & 0.467 \\
\hline B1: Unsafe vehicles & 1.000 & & & & 0.589 \\
\hline B2: Modifications & 0.875 & 0.188 & 4.656 & 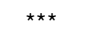 & 0.368 \\
\hline B3: Lack of maintenance & 0.268 & 0.079 & 3.379 & 0.001 & 0.214 \\
\hline C1: Lack of street material & 0.996 & 0.183 & 5.440 & $* * *$ & 0.416 \\
\hline C2: Unfavorable weather & 0.858 & 0.161 & 5.319 & 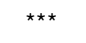 & 0.402 \\
\hline C3: Poor road conditions & 1.000 & & & & 0.467 \\
\hline
\end{tabular}

${ }^{* * *} p<0.001$

Table 5. Standardized coefficient estimates

0.890 and 0.046 , respectively. The result of second-order confirmatory factor analysis (SCFA) confirmed the existence of model about the causal factors in several previous studies reported. Our findings demonstrate that all the candidate factors were related to road traffic accidents. The results of the SCFA are summarized in Table 5.

According to confirmatory factor analysis of second-order, the factors affecting traffic accidents were driving behavior (regression weight $=0.99$ ), followed by attitudes of environment (regression weight $=0.93$ ), and vehicle usage behavior (regression weight $=0.78$ ), as shown in Figure $5(b)$. The dominant cause of traffic accidents was the human factors. Current results indicated that the environmental condition was the important factor contributing to road accidents, such as lack of traffic lights or uneven road surfaces. Our results overall agree with prior reports on traffic accidents in Phuket, with TARC indicating that the main contributing factor in road accidents was the human driver. Lack of awareness of unsafe vehicles and unsafe environment while driving will contribute to road accidents.

\section{DISCUSSION}

In this study, most of the accidents involved motorcycles rather than other vehicle types. Similar results were indicated by the National Statistical Office of Thailand in 2018, reporting 27,623 motorcycle accidents, and 26,818 and 987 passenger car/pick up and bicycle accidents, respectively. The vehicles involved in traffic accidents in this area were similar as in prior reports. The traffic fatality rates of Thailand from accidents are higher than in China, or in Vietnam. Furthermore, the number of registered motorcycles has increased rapidly in Thailand (Chadbunchachai et al., 2012) and this is also observed on Phuket. This is partly because of the rapid emergence of food delivery services from restaurants to residents. Motorcycles have become the most important delivery vehicle of food, drinks, messenger services, or convenience goods. Motorcycles are comparatively inexpensive to acquire and maintain in Thailand. The use of motorcycles is considered convenient and comfortable by the Thai people. However, motorcycle driving can have a high risk, be 
reckless, and cause more accidents than other vehicles do (Tanaboriboon \& Satiennam 2005; Siriliang, 2017; Yongchaitrakul et al., 2012).

The causes related to road accident constructs for people on Phuket were identified including humans, the environment and vehicles. The findings of this study clearly show that the underlying significant factors affecting traffic accidents were risky driving behavior, followed by unsafe environmental, and vehicle conditions. The vital factors involved in occurrence of incidents were human, vehicles, and environment, of which the contribution of human factors was $95 \%$, road and environment 28\%, and vehicles 8\% (Evans, 2012; Zhang, 2019; Uttra et al., 2020). This result also agrees with prior studies (Shinar, 2007; Petridou \& Moustaki, 2000; Sasfarzadeh \& Pooryari, 2006; Hijar et al., 2000). Furthermore, environmental and vehicle conditions contributed to traffic accidents such as poor street lighting, defective road, particularly to those on open roads. In addition, drivers need to have their vehicles checked regularly for effective maintenance.

Most accidents occurred because of driver errors and violations. The results of CFA showed that the drivers' emotions tended to be linked to a high risk of accidents. In general, emotions of people affected the individual behaviors and caused the drivers to adopt inappropriate behaviors, such as riding too close to the vehicle in front or entertaining distractions. Emotions as covert behaviors were considered significant factors contributed to traffic accidents. The effects of negative emotions including snapping, moodiness, or anxiety on driving behaviors increased the risk of accidents. The negative emotions have become one of the most important aspects in management studies. Furthermore, the traffic accidents were directly caused by excessive speed, overtaking, and lack of vigilance, all of those being known unsafe driving behaviors. Current results agreed with Iversen (2004) indicating that the risk behaviors in traffic include dimensions of violation of traffic rules, and reckless driving. Similar findings were confirmed by recent research on the driver behaviors (Yahia \& Ismail, 2011; Aden, 2019; Kankrong, 2015; Boonnuk et al., 2016; Onmek et al., 2020) finding that the main causes of traffic accident were driving behaviors. These studies have shown that unsafe drivers' behaviors are implicated as causes of accidents. This study provided an association between the risky driving behaviors of human with accidents in road traffic. The recommended measure to take is that the traffic management team in Phuket needs to effectively deploy formal policy awareness among the drivers for improved safety.

\section{CONCLUSIONS}

In this study the participating drivers were males, aged between 21 and 40 years, and mostly worked as company employees. Motorcycle accidents were the most common accident type on Phuket island. In addition, most drivers had over 9 years of driving experience and had a motorcycle driving license. The accidents were more likely to occur during daytime than in night-time. The results of the study indicate that the driving behaviors, vehicle, and environmental factors are all related to road traffic accidents. Our findings demonstrate that the human factors were dominant causes of traffic accidents in second-order confirmatory factor analysis. Major causes of traffic accidents were unsafe driving practices, such as aggressive driving under a relevant emotional state or speedy driving. Unsafe acts caused by emotional status that were at extremes of any of these dimensions would be dangerous for driving. Decreasing human errors in road traffic needs to be the focus, by toning down emotional responses or managing the driving speeds. Proper training with adequate skills needs to be provided to unsafe drivers before returning their vehicles, in dangerous and careless driving cases. The way to build road safety awareness includes strict enforcement of laws, and this should be supported. The study also raised a point that the road infrastructure, especially road surfaces, should be improved to reduce accidents. This is easier than trying to manipulate other contributing factors like human behaviors or vehicle conditions. This study was limited to a sampling on Phuket island. Future studies should expand the scope to other provinces in Thailand. A solution to assist the drivers, which detects abnormal driving behaviors, could be developed in the future using a mobile application for providing automatic alerts.

\section{ACKNOWLEDGEMENTS}

The authors of this article would like to thank the Prince of Songkla University, Surat Thani Campus, for funding support; and the people of Phuket island for participating in the survey of this study.

\section{REFERENCES}

Aden W. A., 2019. A comparative study on the characteristics of road traffic accidents in China and Djibouti. American Scientific Research Journal for Engineering, Technology, and Sciences (ASRJETS), 55, pp. 204-225.

Ajzen, I., Fishbein, M., 1980. Understanding attitudes and predicting social behavior. Prentice-Hall, Englewood Cliffs, NJ.

Atkinson, T. M., et al., 2011. Using confirmatory factor analysis to evaluate construct validity of the brief pain inventory (BPI). Journal of Pain and Symptom Management, 41, pp. 558-565.

Bentler, P., \& Stein, J., 1992. Structural equation models in medical research. Stat Methods Med Res, 1, pp. 159-181. doi:10.1177/096228029200100203.

Boonnuk, T., Rudtanasudjatum, K., Methaphat, C., Yingratanasuk, T., 2016. Risk factors on behavior and impairments of motorcycle riders in an industrial areas affecting the severity of traffic accidents. Journal of Public Health, 46, pp. 261-270.

Brown, T. A., 2015. Confirmatory factor analysis for applied research (2nd ed.) New York: Guilford Publications.

Chadbunchachai, W., Suphanchaimaj, W., et al., 2012. Road traffic injuries in Thailand: Current situation. J Med Assoc Thai, 95, pp. 274-281. http://jmat.mat.or.th/.

Chumpawadee, U., Homchampa, P., Thongkrajai. P., et al., 2015. Factors related to motorcycle accident risk behavior among university students in northeastern Thailand. Southeast Asian J. Trop. Med. Public Health, 46(4), pp. 805-821.

Coogan, M., Margaret, C. Thomas, et al., 2014. Examining behavioral and attitudinal differences among groups in their traffic safety culture. Transportation Research Part F, 26, pp. 303-316.

Evans, L., 2012. Human Behavior and Traffic Safety; Springer Publishing Company: New York, NY, USA.

Fishbein, M., Ajzen, I., 1975. Belief, attitude, intention, and behavior: An introduction to theory and research. Addison-Wesley, Reading, MA.

Gunson, H. P., Beanland, V., \& Salmona, P.M., 2019. Road-related anger in motorcyclists versus car drivers. Transportation Research Part F: Traffic Psychology and Behaviour, 62, pp. 327-338.

Habibi, E., Haghi, A., \& Maracy, M. R., 2014. Investigating the predictive of risk-taking attitudes and behaviors among Iranian drivers. Journal of Education and Health Promotion, 3, pp. 6-11. doi:10.4103/2277-9531.127599.

Haddon, J. W., 1972. A logical framework for categorizing highway safety phenomena and activity, J Trauma, 12, pp. 193-207.

Haddon, J. W., 1968. The Changing approach to the epidemiology, prevention, and amelioration of trauma: the transition to approaches etiologically rather than descriptively based. American Journal of Public Health, 58, pp. 1431-1438. 
Hair, J. F., Black, W. C., et al., 2014. Multivariate data analysis (7th ed.). Harlow: Pearson Education Limited Edinburgh Gate.

Heinrich, H.W., 1931. Industrial accident prevention; a scientific approach. McGraw-Hill.

Helal, R., El-Khawaga, G., et al. 2018. Perception and Practice of Road Safety among Medical Students, Mansoura, Egypt. Osong Public Health Res Perspect, 9(1), pp. 25-31.

Hijar, M., Carrillo, C., et al., 2000. Risk factors in highway traffic accidents: A case control study. Accid Anal Prev, 32, pp. 703-709. doi:10.1016/s0001-4575(99)00116-5.

Hosseinian, S. S., Torghabeh, Z. J., 2012. Major theories of construction accident causation models: a literture review. International Journal of Advances in Engineering \& Technology, 4(2), pp. 53-66.

Iversen H.,2004. Risk-taking attitudes and risky driving behaviour. Transportation Research Part F: Traffic Psychology and Behaviour, 7, pp. 135-150.

Kankrong, P., 2015. A study of young driver behavior that affect the risk of accidents from the motorcycle; Suranaree University of Technology: Nakhon Ratchasima, Thailand.

Kongcharoen, J., Onmek, N., et al., 2020. Stress and work motivation of primary and second school teachers. Journal of Applied Research in Higher Education, 12, pp. 709-723.

Liu, G., Chen, S., Zeng, Z., et al., 2018. Risk factors for extremely serious road accidents: results from national road accident statistical annual report of China. PLoS, 13, pp. 1-18.

Lund, J., \& Aaro, L.E. 2004. Accident prevention. Presentation of a model placing emphasis on human, structural and cultural factors. Safety Science, 42, pp. 271-324.

Mehdizadeh, M., Shariat-Mohaymany, A., Nordfjaern, T., 2018. Accident involvement among Iranian lorry drivers:Direct and indirect effects of background variables and aberrant driving behaviour. Transportation Research Part F, 58, pp. 39-55.

Mirzaei, R., Hafezi-Nejad, N. et al., 2014. Dominant role of drivers' attitude in prevention of road traffic crashes: A study on knowledge, attitude, and practice of drivers in Iran. Accident Analysis \& Prevention, 66, pp. 36-42.

Mohamed, M., \& Bromfield, N. F., 2017. Attitudes, driving behavior, and accident involvement among young male drivers in Saudi Arabia. Transportation Res. Part F Traffic Psychology \& Behaviour, 47, pp. 59-71.

Onmek, N., Kongcharoen, J., et al., 2020. A causal relationship model of psychological factors relating to unsafe driving behaviors in Phuket. The Public Health Journal of Burapha University, 15, pp. 13-24.

Özkan, T., Lajunen, T., et al., 2012. Motorcycle accidents, rider behaviour, and psychological models. Accident Analysis \& Prevention, 49, pp. 124-132.

Pakgohar, A., Tabrizi, R. S., et al., 2011. The role of human factor in incidence and severity of road crashes based on the CART and LR regression: A data mining approach. Procedia Computer Science, 3, pp. 764-769.

Parker, D., Manstead, A. S. R., Stradling, S. G., Reason, J. T., \& Baxter, J. S., 1992. Intention to commit driving violations: An applications of the theory of planned behavior. Journal of Applied Psychology, 77, pp. 94- 101.

Parker, D., Reason, J., et al., 1995. Driving errors, driving violations and accident involvement, Ergonomics, 38(5), pp. 1036-1048. doi: 10.1080/00140139508925170.

Petridou, E., \& Moustaki, M., 2000. Human factors in causation of road traffic crashes. Eur J Epidemiol, 16, pp. 819-826.

Porter, B. E., 2011. Handbook of traffic psychology (1st ed.). London; Waltham, MA: Academic Press.

Reason, J., Manstead, A., et al., 1990. Errors and violations on the roads: a real distinction? Ergonomics, 33, pp. 1315-1332. doi:10.1080/00140139008925335.

Rosli, N. et al., 2017. Testing the Driving Behavior Questionnaire (DBQ) on Malaysian drivers. The Proceeding of the 12th Malaysian Universities Transport Research Forum Conference
(MUTRFC 2017). In Conjunction With 4th Agkn On Tour 15. Universiti Teknologi Mara, Selangor.

Royal Thai Police. 2018. Traffic Accident on National Highways in 2018. Thailand: Royal Thai Police.

Sasfarzadeh, M.\& Pouryari, M., 2006. An analytical model for the determination of road safety index. Modares Technical and Engineering, 25, pp. 29-40.

Saxena, N., 2017. Road Traffic Accident using Causation Theory with Traffic Safety Model and Measures. International Journal for Research in Applied Science \& Engineering Technology (IJRASET), 5, pp. 1263-1269.

Schreiber, J. B., et al., 2006. Reporting structural equation modeling and confirmatory factor analysis results: A review. The Journal of Educational Research, 99, pp. 323-336.

Shinar, D., 2007. Traffic Safety and Human Behavior. Bingley, UK, Howard House: Emerald Group Publishing Limited.

Siriattakul, P., 2014. A Confirmatory factor analysis for mental health of adolescents in eastern region, Thailand. Journal of Interdisciplinary Research: Graduate Studies, 3, pp. 1-11.

Siriliang, R., 2017. Casual model development for traffic accidents of motorcyclists in Loei Province. The Public Health Journal of Burapha University, 12, pp. 15-26.

Stephensa, A.N., Brownb, J. et al., 2017, The relationship between Motorcycle Rider Behaviour Questionnaire scores and crashes for riders in Australia. Accident Analysis and Prevention, 102, pp. 202-212.

Suangka, K., 2016. A study of young driver behavior that affect the risk of accidents from the motorcycle. Nakhon Ratchasima: Suranaree University of Technology.

Sullman, M. J., \& Stephens, A. N., 2013. A comparison of the driving anger scale and the propensity for angry driving scale. Accid Anal Prev, 58, pp. 88-96.

Suraji, A., \& Tjahjono, N., 2012. A confirmatory factor analysis of accidents caused by the motorcycle aspect in urban area. IJTTE, 2, pp. 60-69.

Tanaboriboon, Y. \& Satiennam, T., 2005. Traffic Accidents in Thailand, IATSS Research, 29, pp. 88-100. https://doi.org/10.1016/S0386-1112(14)60122-9.

Thanakarnpanich, N., 2013. Causal model on self-regulation : A comparison between SEM and MRA. Journal of Research Methodology, 26, pp. 213-241.

Thasai, K., Musigapong, P., \& Pundee, R. 2021. Factors affecting risk behaviors influencing motorcycle accident among senior high school students. Journal of Safety and Health, 14(1), pp. 50-67.

Theofilatos, A., \& Yannis, G., 2014. A review of the effect of traffic and weather characteristics on road safety. Accident Analysis and Prevention, 72, pp. 244-256.

Uttra, S., Jomnonkwao, S., et al., 2020. Development of selfassessment indicators for motorcycle riders in Thailand: Application of the motorcycle rider behavior questionnaire (MRBQ). Sustainability, 12, pp. 1-16. doi:10.3390/su12072785.

Vanichbuncha, K., 2019. Structural equation model (SEM) using AMOS. Bangkok: Chulabook. ISBN: 9786164789166. www.chulabook.com/en/product-details/20687.

Verster, T., \& Fourie, E., 2018. The good, the bad and the ugly of South African fatal road accidents. South African Journal of Science, 14, pp. 1-7. https://www.sajs.co.za/article/ view/4287.

Vongurai, R. 2018. The influence of Thailand's image and foreign tourist satisfaction on foreign tourist loyalty for Thailand. International Journal of East Asia Studies, 22, pp. 2-21.

Wallston, K., \& Wallston, B., 1978. Who is respondsible for your health locus of control. Social Psychology of Health and Illness. Lawrence Erlbaum Associated Publishers.

Wang, C., Xu, Chengcheng, et al., 2018. The effects of safety knowledge and psychological factors on self-reported risky driving behaviors including group violations for e-bike riders in China. Transportation Research Part F, 56, pp. 344-353. 
Wicker, A.W., 1969. Attitudes versus actions: the relationship of verbal and overt behavioral responses to attitude objects. Journal of Social Issues, 25(4), pp. 41-78.

WHO: World Health Organization., 2018. Global status report on road safety 2018. Switzerland: World Health Organization.

Yahia, H. A., \& Ismail, A., 2011. Analysis of traffic accidents in Libya. International Building \& Infrastructure Technology Conference 7-8 June Vistana Hotel. Penang, Malaysia. https://www.researchgate.net/publication/323120632.

Yamane, T., 1973. Statistics: An Introductory Analysis (3rd ed.). New York: Harper \& row.

Yau, K. K., 2004. Risk factors affecting the severity of single vehicle traffic accidents in Hong Kong. Accident Analysis and Prevention, 36, pp. 333-340.

Yongchaitrakul, T., Juntakarn, C., et al., 2012. Socioeconomic inequality and road traffic accidents in Thailand: Comparing cases treated in government hospitals inside and outside of Bangkok. Southeast Asian J Trop Med Public Health, 43, pp. 785-794.

Zhang, G., Yau, K. K., et al., 2013. Risk factors associated with traffic violations and accident severity in China. Accident Analysis \& Prevention, 59, pp. 18-25.

Zhang, Y., Jing, L., et al., 2019. Human factors related to major road traffic accidents in China. Traffic Injury Prevention, 20, pp. 796-800. doi:10.1080/15389588.2019.1670817. 